\title{
Uma aValiação inicial do CuRso de licenciatura INTEGRADA EM MATEMÁTICA E FÍSICA DA UFOPA/PA
}

\author{
AN INITIAL ASSESSMENT OF THE INTEGRATED DEGREE COURSE IN \\ MATHEMATICS AND PHYSICS AT UFOPA/PA
}

DOI: http://dx.doi.org/10.23926/RPD.2526-2149.2019.v4.n2.p411-430.id464

\section{José Ricardo e Souza Mafra \\ Doutor em Educação \\ (UFRN) \\ Professor na Universidade \\ Federal do Oeste do Pará \\ (UFOPA) \\ jose.mafra@ufopa.edu.br}

Neliane Mota Rabelo

Mestre em Educação

(UFOPA)

neliane.rabelo@ufopa.edu.br

\section{Cassio André Sousa da \\ Silva}

Doutor em Engenharia

Elétrica (UFPA)

Professor na Universidade

Federal do Oeste do Pará

(UFOPA)

cassio.ufpa@yahoo.com.br

\section{Lilian Cristiane}

Almeida dos Santos

Doutora em Ensino de

Ciências (USP)

Professora na Universidade

Federal do Oeste do Pará

(UFOPA)

lilicrissantos@gmail.com
Resumo: Este trabalho tem por objetivo trazer apontamentos e resultados de uma pesquisa avaliativa, realizada com os discentes do curso de Licenciatura Integrada em Matemática e Física (LIMF), vinculado à Universidade Federal do Oeste do Pará, na cidade de Santarém/PA. Tal pesquisa avaliativa está prevista no Projeto Pedagógico de Curso (PPC), a ocorrer, em média, de três em três anos, de forma a subsidiar reformulações e ajustes necessários, visando a melhorias no curso. Entre 2017 e 2018 foram aplicados questionários nas turmas correntes, de forma a extrair informações pertinentes dos discentes, subsidiando assim a coordenação e o conjunto de professores a discutirem os aspectos pertinentes ao desenvolvimento operacional e aperfeiçoamento das ações relativas à dinâmica do processo formativo, objeto de existência do curso. Os questionários foram aplicados a partir de uma amostra de 56 discentes, de um total de 177 matriculados. Os resultados apresentados mostram informações avaliativas, tanto positivas quanto negativas, em relação ao curso, projetando assim uma análise crítica, visando ao seu aperfeiçoamento e à sua melhoria.

Palavras-chave: Ensino; Avaliação; Formação docente; PPC.

Abstract: This work aims to bring notes and results of an evaluative research, conducted with the students of the Integrated Degree in Mathematics and Physics (LIMF), linked to the Federal University of West Pará, in the city of Santarém/PA. Such evaluative research is foreseen in the political pedagogic project (PPC), to take place, on average, every three years, in order to subsidize reformulations and necessary adjustments, aiming at improvements in the course. Between 2017 and 2018, questionnaires were applied to the current classes, in order to extract relevant information from the students, thus supporting the coordination and the set of teachers to discuss the aspects relevant to the operational development and improvement of the actions related to the dynamics of the training process, object of the course existence. The questionnaires were applied from a sample of 56 students, out of a total of 177 enrolled. The results presented show evaluative information, both positive and negative, in relation to the course, thereby projecting a critical analysis, aiming at its improvement and its enhancement.

Keywords: Teaching; Evaluation; Teacher training; PPC. 


\section{INTRODUÇÃO}

Um dos grandes desafios propostos pela Lei 9.394/1996 (BRASIL, 1996) está em suas disposições transitórias, quando é instituída a década da educação. Ao final dessa década todos os professores do ensino básico devem possuir diploma do ensino superior. Decorridos mais de 20 após a promulgação da Lei de Diretrizes e Bases (LDB) e, mesmo com as ações implementadas e em vias de implementação, propostas pelo Plano Nacional de Educação (PNE) (BRASIL, 2014), em determinadas regiões do país, a maioria das escolas ainda possui ausência de professores qualificados e, em outras, existe falta de pessoal para cumprir a demanda do ensino básico. Um exemplo disso está indicado em um trabalho desenvolvido pelo Instituto de Pesquisa Econômica e Aplicada (IPEA), o qual apresenta um panorama dos professores da educação básica no Brasil (IPEA, 2017). Neste estudo, é apresentada, dentre outras informações, a distribuição de professores da educação básica, de acordo com escolaridade total, segundo região, situação de domicílio e inserção por tipo de escola no trabalho docente principal. Mais especificamente, na Região Norte, temos um percentual significativo de professores que ali atuam, mas que ainda não possuem um curso superior completo ou que são formados em uma habilitação e ministram aulas em outras áreas de conhecimento.

Em se tratando de uma formação inicial que procure agregar conhecimentos da área de Matemática, em conjunto com a área da Física, de uma forma integrada, percebemos que não é uma tarefa simples. Em especial, quando se pretende aprender coisas que para nós já se consideram certas, em se tratando de objetos matemáticos, por exemplo, e mais ainda, quando se pretende aprender a ensinar a física, através das explicações de seus fenômenos (por meio destes mesmos objetos matemáticos). É preciso um trabalho de reestruturação de conteúdos de modo a tornar o aprendizado do futuro professor licenciado mais eficiente. Aliado a isso, vem a necessidade de novas técnicas e métodos de ensino que permitam novas abordagens de certos tópicos. Nesse aspecto, a informática e a tecnologia têm seu papel relevante. Em uma sociedade cada vez mais dependente de recursos computacionais é de fundamental importância que os futuros professores saibam lidar com um computador e absorver as possibilidades educacionais que esta máquina pode oferecer: jogos matemáticos, aplicativos para resolução de problemas geométricos, simuladores para experimentos da Física, pesquisa na Internet, software avançados de Matemática e Física, entre outros.

Tais iniciativas podem trazer várias implicações e, de fato, isso ocorreu, conforme veremos nas seções posteriores. Com base nestas considerações, este trabalho apresenta apontamentos e resultados de uma pesquisa avaliativa, realizada com os discentes do curso de 
Licenciatura Integrada em Matemática e Física, vinculado a Universidade Federal do Oeste do Pará (UFOPA), na cidade de Santarém/PA. Os resultados a serem apresentados, permitirão discutir o quanto o ambiente de trabalho na perspectiva que o curso se propõe, fornece cenários desafiadores e exigentes, em que o nível de tensão e de complementariedade adquire uma percepção fortemente ancorada na necessidade de inovação e de diferentes perspectivas de formação. Em que pese as limitações, dificuldades e necessidades, inerentes a qualquer proposta de curso novo, espera-se que o perfil formativo proposto, permita fornecer aos discentes, um preparo maior para enfrentar a difícil tarefa de sobreviver e viver, em um mundo em que a qualificação é cada vez mais exigida. Isto é um salto significativo para o desenvolvimento do estado do Pará, em especial a região oeste do Pará, que terá a médio e longo prazo, pessoas cada vez mais capazes de enfrentar os problemas que surgem em seu diaa-dia.

\section{O CURSO DE LIMF/UFOPA}

Tendo em vista as considerações informadas na seção anterior, ainda muito presente, na região oeste do Pará, a UFOPA, através do Programa de Ciências Exatas (PCE), propôs um projeto pedagógico de um curso de Licenciatura Integrada em Matemática e Física (LIMF). Esta proposta, procura ir de encontro a perspectivas e anseios do ensino básico brasileiro, em especial do Estado do Pará, pois, em sua proposta considera as características peculiaridades e demandas da região norte do país, além de se propor a inovar na formação dos jovens egressos do ensino médio. Sua proposta, basicamente, procura fomentar uma formação articulada entre a matemática e a física, oferecendo assim uma perspectiva de formação alternativa, combinando duas áreas de conhecimento, com importância significativa, na educação brasileira, projetando assim, uma demanda de formação de professores para as redes Estadual e Municipal da Educação Básica.

De acordo com o PPC - LIMF, o objetivo do curso é:

Formar professores de Matemática e Física com domínio dos conhecimentos específicos em Matemática Física e habilidades necessárias para ensinar essas disciplinas na região amazônica, respeitando as peculiaridades regionais, visando contribuir com o desenvolvimento da educação básica na região (UFOPA, 2015, p. 23).

Em Rabelo (2019), encontramos uma síntese das principais informações relacionadas ao curso de LIMF. O Projeto Pedagógico de Curso (PPC), de LIMF, foi aprovado através da Resolução n. 125, de 22/09/2015, pelo Conselho Superior de Ensino, Pesquisa e Extensão 
(CONSEPE), da UFOPA. O curso apresenta uma proposta de formação integrada nas áreas de matemática e física, apresentando um total de 3.890 horas, distribuídos em um tempo mínimo de 9 semestres e tempo máximo de 15 semestres. O PPC delineia a preocupação em formar profissionais que tenham conhecimentos, tanto da área de matemática como da área de física, além de destacar a importância do uso da informática, consequentemente das tecnologias, na formação inicial dos aprendizes, tal como indicado abaixo:

\footnotetext{
Nesse aspecto, a informática tem seu papel relevante. Em uma sociedade cada vez mais dependente de recursos computacionais é de fundamental importância que os futuros professores saibam lidar com um computador e absorver as possibilidades educacionais que esta máquina pode oferecer: jogos matemáticos, aplicativos para resolução de problemas geométricos, simuladores para experimentos da Física, pesquisa na Internet, softwares avançados de Matemática e Física, entre outros (UFOPA, 2015, p.22).
}

Consta em seu perfil profissional do egresso atender algumas competências, dentre elas "Demonstrar capacidade de atuação em áreas afins da habilitação, inclusive adaptação às novas tecnologias, facilitando sua inserção crítica e competente no mercado de trabalho" (UFOPA, 2015, p.27).

O PPC segue as diretrizes curriculares nacionais para os cursos de licenciatura em Matemática e licenciatura em Física e, atualmente, está em processo de atualização, por conta das exigências estabelecidas na Resolução $n^{\circ} 02$, de $1^{\circ}$ de julho de 2015 que define as Diretrizes Curriculares Nacionais para a formação inicial ao nível superior (cursos de licenciatura, cursos de formação pedagógica para graduados e cursos de segunda licenciatura).

No ano de 2019, decorrido o primeiro ciclo avaliativo do curso, deu-se início o processo de revisão/reformulação de seu PPC, através das ações desenvolvidas pelo seu Núcleo Docente Estruturante (NDE), em conjunto com o colegiado de curso e contribuições dos discentes, geradas a partir da aplicação de um instrumento de obtenção de dados, em forma de um questionário.

\section{O PROCESSO DE AVALIAÇÃO PROJETADO PARA O CURSO DE LIMF}

A proposta de avaliação projetada para o curso, versa sobre os mecanismos e estratégias a serem dimensionadas (UFOPA, 2015), visando o aperfeiçoamento e melhorias a serem realizadas no PPC. A avaliação é uma questão desafiadora e complexa, a qual sempre vai apresentar elementos desafiadores a serem otimizados e implementados. Entendemos que, novas e melhores oportunidades de aprendizagem devem ser garantidas, com diferentes instrumentos de avaliação. Para D’Ambrósio (1996, p.70), “[...] a avaliação serve para que o 
professor verifique o que de sua mensagem foi passado, se seu objetivo de transmitir ideias foi atingido - transmissão de ideias e não aceitação e a incorporação dessas ideias e muito menos treinamento". Nesse sentido, quanto à avaliação de aprendizagem, o importante é que seja durante todo o ano letivo e não somente em algumas datas pré-estabelecidas, caracterizando assim um processo temporal extenso", pois, como afirma Libâneo (1992):

\footnotetext{
A avaliação é uma tarefa didática necessária e permanente no trabalho docente, que deve acompanhar passo a passo, o processo de ensino e aprendizagem. Através dela, os resultados propostos vão sendo obtidos, de modo a constatar progressos, dificuldades e reorientar o trabalho escolar tanto do professor como dos alunos (LIBÂNEO, 1992, p.195).
}

Ou seja, a avaliação deve ajudar o professor no processo de conhecer seus alunos e preparar atividades adequadas. Além disso, um dos grandes desafios desta formação é o de proporcionar uma avaliação satisfatória para o conjunto integrante do mesmo (alunos, professores e técnicos administrativos), agregando a participação ativa dos integrantes da universidade, nas atividades oferecidas ao longo dos períodos letivos de oferta de disciplinas e demais ações relacionadas ao processo de integralização curricular. (UFOPA, 2015). Estes encaminhamentos podem permitir o aprimoramento gradativo e permanente da aquisição do conhecimento, possibilitando o aumento, em qualidade, na formação do professor de Matemática e Física. Para isso, a avaliação no Curso de LIMF deve utilizar diferentes instrumentos avaliativos, tais como uma revisão periódica de disciplinas da grade curricular, acompanhamento do rendimento dos alunos da universidade via indicadores estatísticos, formulados pela coordenação, mostrando níveis de aprovação e evasão, conforme indicações propostas nos documentos institucionais. Tais aspectos também poderão ser úteis para a formulação de outros indicadores, tais como os propostos pela própria instituição, pela Comissão Própria de Avaliação (CPA), para: docentes, egressos, dinâmica de funcionamento do curso, auto avaliação, etc.

A avaliação do Projeto Pedagógico do Curso é essencial para reconhecer as dificuldades e as facilidades encontradas durante o desenvolvimento do curso. Cabe ao Programa de Ciências Exatas, em conjunto com seus professores discutirem e refletir sobre formas alternativas de instrumentos de avaliação na área. Estas características relacionadas à avaliação coincidem com a proposição do objetivo da Avaliação Institucional Interna da UFOPA, no sentido de desenvolver um processo permanente de avaliação institucional, visando o aprimoramento do gerenciamento administrativo e acadêmico. 
O PPC do curso de LIMF (UFOPA, 2015) projeta assim, a sua avaliação, considerando proporcionar:

[...] melhorias e inovações e que permite identificar possibilidades, orientar, justificar, escolher e tomar decisões em relação às experiências vivenciadas, aos conhecimentos disseminados ao longo do processo de formação profissional e a interação entre o curso e os contextos locais, regional e nacional. Tal avaliação deverá levantar a coerência interna entre os elementos constituintes do Projeto e a pertinência da estrutura curricular em relação ao perfil desejado e o desempenho social do egresso, para possibilitar que as mudanças se deem de forma gradual, sistemática e sistêmica. Seus resultados subsidiarão e justificarão reformas curriculares, solicitação de recursos humanos, aquisição de material, etc. Sendo assim, a avaliação do Projeto Pedagógico será realizada, em média, a cada três anos, com a participação da comunidade para sua readequação e também para servir de retroalimentação do processo e fundamentação para tomada de decisões institucionais, que permitam a melhoria da qualidade de ensino. (UFOPA, 2015, p. 52)

Estas ações internas, mostram-se pertinentes, quando se fornecem elementos motivadores versando a preparação do curso para futuros pareceres externos, haja vista que o mesmo é periodicamente submetido às avaliações dos órgãos governamentais, através do Exame Nacional de Desempenho dos Estudantes (ENADE), elaborado pelo Ministério da Educação (MEC) e também é um dos indicadores observados pelas comissões de avaliadores in loco designados pelo MEC.

O acompanhamento ou processo de avaliação é um dos momentos mais importantes envolvendo qualquer processo, quer seja ele acadêmico ou não. O mais importante dentro de um processo avaliatório são os instrumentos e os critérios que são utilizados como referenciais para efetuar o processo avaliativo de um determinado evento ou ação. Nesse sentido, o colegiado do curso entende que uma avaliação periódica é muito pertinente, levando-se em consideração vários momentos pelos quais irá passar. Havendo necessidade de surgimento de novas demandas ou técnicas inovadoras e métodos de ensino, a serem propostos, o curso de LIMF através dos resultados obtidos da apreciação interna deverá se adequar primando sempre pela qualidade na formação desses futuros profissionais da educação. Com base nestas afirmações, o PPC - LIMF será avaliado sistematicamente por meio de relatórios e instrumentos de recolha de informações, elaborados pelo Programa de Ciências Exatas, através de sua coordenação de curso, visando refletir sobre o cumprimento de suas prerrogativas básicas, tais como: seus objetivos, perfil do profissional, habilidades e competências, estrutura curricular, pertinência do curso no contex to regional, corpo docente e discente.

Nesse sentido, conforme preconiza o PPC do curso de LIMF (UFOPA, 2015):

A avaliação do Projeto Pedagógico deve ser considerada como ferramenta construtiva que contribui para melhorias e inovações e que permita identificar possibilidades, orientar, justificar, escolher e tomar decisões em relação às experiências vivenciadas, 
aos conhecimentos disseminados ao longo do processo de formação profissional e a interação entre o curso e os contextos local, regional e nacional. Tal avaliação deverá levantar a coerência interna entre os elementos constituintes do Projeto e a pertinência da estrutura curricular em relação ao perfil desejado e o desempenho social do egresso, para possibilitar que as mudanças se deem de forma gradual, sistemática e sistêmica. Seus resultados subsidiarão e justificarão reformas curriculares, solicitação de recursos humanos, aquisição de material, etc. (UFOPA, 2015, p. 52).

Sendo assim, a avaliação do PPC - LIMF, conforme indicado anteriormente, projeta uma discussão, em média, a cada três anos, com a participação da comunidade para sua readequação e também para servir de retroalimentação do processo e fundamentação para tomada de decisões institucionais, que permitam a melhoria da qualidade de ensino. Com base nestas considerações, elaboramos um instrumento avaliativo de forma a obter, do seguimento discente, impressões sobre a dinâmica de funcionamento do curso, desde a sua implementação até o momento em que a mesma foi aplicada.

\section{ASPECTOS METODOLÓGICOS ENVOLVIDOS NO PROCESSO DE AVALIAÇÃO REALIZADO}

Visando obter informações relacionadas com o objeto de discussão deste trabalho, realizamos em 2017 a aplicação de questionários, nas turmas correntes, dos anos: 2013, 2014, 2015 e 2016. Por uma questão metodológica, optou-se em excluir, em um primeiro momento as turmas do ano de 2017 e 2018, sendo que as informações destas turmas serão incorporadas no próximo ciclo de avaliação do curso, previsto para ocorrer no próximo ano.

Tal iniciativa tinha como proposta inicial, subsidiar a coordenação e o conjunto de professores e discentes da LIMF a discutirem os aspectos pertinentes ao desenvolvimento operacional e aperfeiçoamento das ações relativas à dinâmica do processo formativo, objeto de existência do curso. Mesmo tendo ciência, das limitações deste instrumento de pesquisa (MARCONI e LAKATOS, 2011), optamos em formular um questionário, conforme Figura 1, com perguntas abertas e semiestruturadas, de forma a fornecer informações decorrentes das vivências dos discentes, em relação ao desenvolvimento das ações do curso, a desempenho docente, gerenciamento do curso, estrutura e ordenação das disciplinas integrantes do PPC, dentre outros aspectos relacionais e relevantes.

\section{Figura 1 -}


Figura 1 - Questionário aplicado

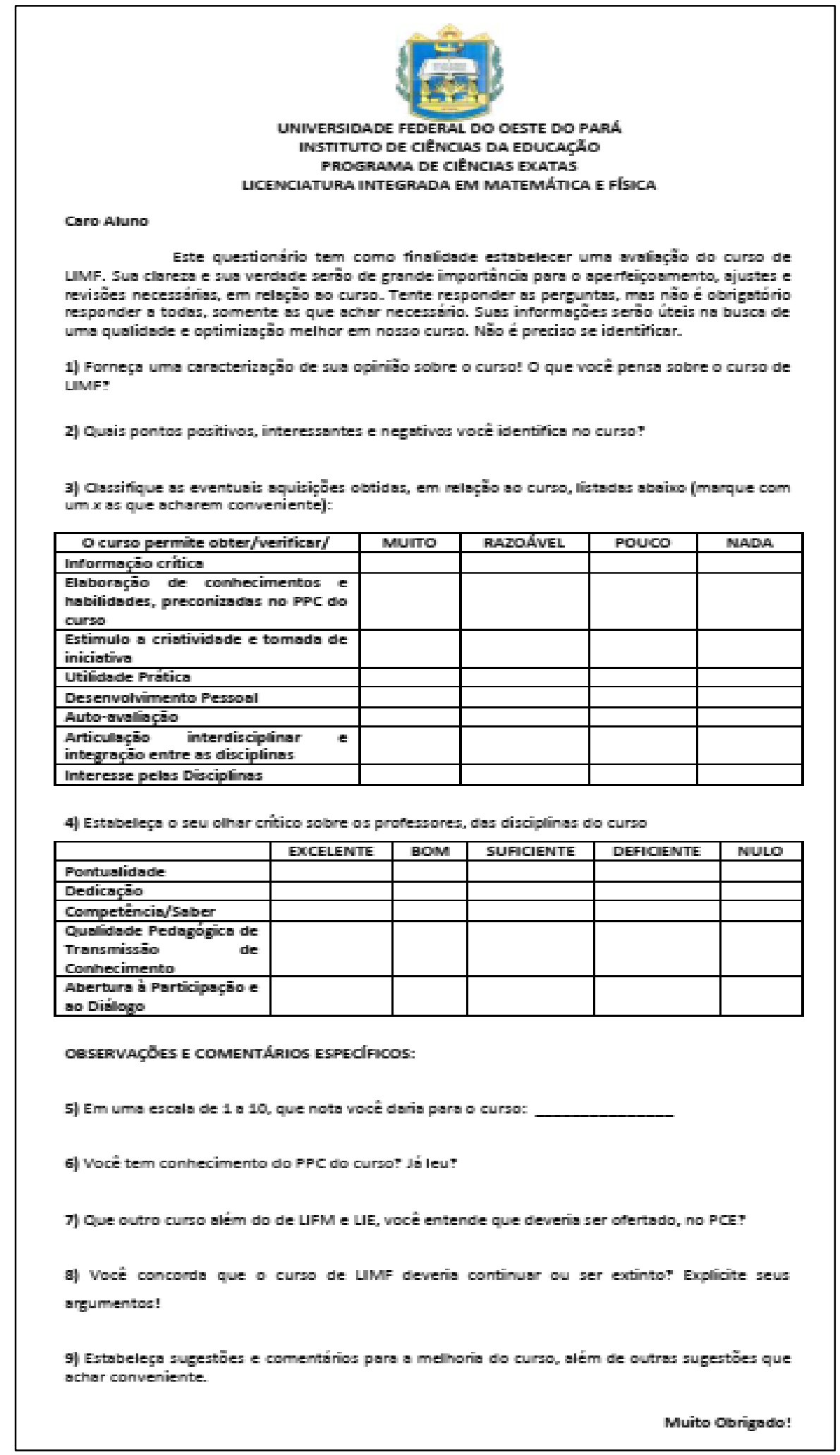

Fonte: adaptado de Vergani (1995)

Os questionários foram aplicados, a partir de uma amostra de 56 acadêmicos, de um total de 177 discentes matriculados, na época da realização da pesquisa, perfazendo uma 
somatória de $31,63 \%$ de respondentes, em relação ao total de discentes matriculados e a tabulação, e organização dos dados foram realizadas no ano de 2018, razão pela qual apresentamos as informações somente agora.

O critério para a escolha da amostra, tomou como base os discentes matriculados nas turmas do curso de LIMF e que estavam em um percurso intermediário, como trajetória acadêmica, ao longo do processo de integralização da licenciatura. Os critérios de análise do conjunto de informes obtidos foram desenvolvidos com base nos resultados adquiridos, tal como dos registros de depoimentos informados, observando-se os relatos e discursos envolvidos na escrita dos universitários, conforme indica Bardin (2011), ao projetar uma discussão sobre estratégias e orientações metodológicas para realizar uma correta Análise de Conteúdo. Assim, o conjunto de informes obtidos foram correlacionadas com as informações e diretrizes de avaliação propostas pelo PPC e pela literatura estudada e de fundamentação, para esta proposta. Por questões éticas, os questionários respondidos pelos discentes não foram identificados.

Na próxima seção, apresentamos as referências fornecidas pelos discentes, fornecendo, logo em seguida, uma análise reflexiva sobre os principais destaques, projetando assim, nas considerações finais, conclusões e encaminhamentos.

\section{O QUE DIZEM OS DISCENTES, SOBRE O CURSO DE LIMF?}

Ao analisarmos os dados obtidos dos questionários, as duas questões iniciais, formulada, tratava da opinião dos educandos em relação ao curso: 1) Forneça uma caracterização de sua opinião sobre o curso! O que você pensa sobre o curso de LIMF? 2) Quais pontos positivos, interessantes, e negativos você identifica no curso de LIMF?

A seguir apresentaremos um panorama das informações fornecidas pelos discentes, a partir de um quadro que delineia categorias organizadas, com base nas respostas dos discentes, no Gráfico 1. 
Gráfico 1 - Opinião dos discentes sobre o curso de LIMF

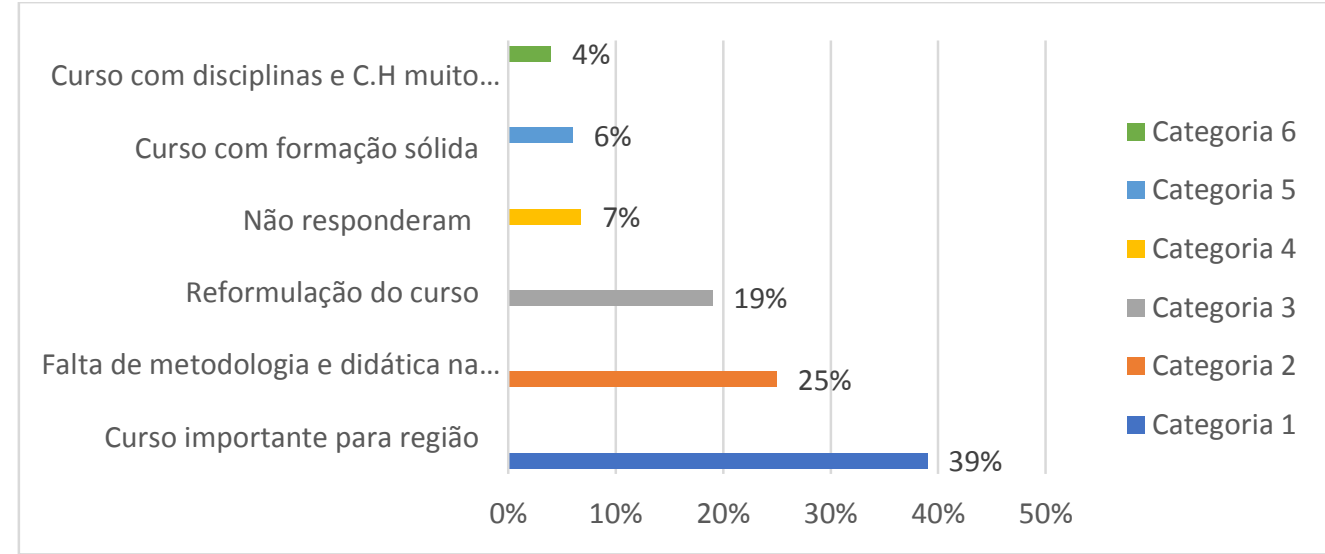

Fonte: Questionário aplicado na avaliação interna do curso, 2017.

Com base em Bardin (2011), foram categorizadas as informações, tendo como resultado seis categorias que serão discutidas a seguir.

As respostas dos educandos nas categorias 1 delineiam que o curso se mostra importante para a formação na região, pois 39\% (28 discentes) consideram o curso de LIMF, rico, inovador, referência e essencial para construção dos futuros profissionais atendendo as especificidades regionais. Destes, 01 aluno conceitua curso composto por bons professores e 01 outro considera o ensino ótimo. Assim, apresenta-se em conformidade com o disposto no objetivo geral do currículo (UFOPA, 2015) que visa formar professores que atuem nas disciplinas de matemática e física, respeitando as peculiaridades do território amazônico.

$\mathrm{Na}$ categoria 2, falta de metodologia e didática, na prática docente nota-se insatisfações e lacunas (perfazendo 25\%) que são apresentadas por 15 discentes, pois se percebe que o curso apresenta uma estrutura voltada para o bacharelado e não para um curso de licenciatura. Destacam a preocupação na falta de didática dos docentes, desta maneira deixam, explicito que consideram que o curso deveria ser mais dinâmico com metodologias variadas. Essas opiniões são oriundas do atual cenário em que a sociedade passa por constantes mudanças interferindo de forma direta na formação universitária. Para Assis (2012, p. 57), “É ‘mister’ criar condições para um processo permanente de articulação dos diferentes saberes, valorizando a dinâmica de construção colaborativa". Nesse contexto, justificam-se as opiniões dos universitários que buscam uma formação acadêmica de professores qualificados para os tempos atuais.

$\mathrm{Na}$ categoria 3, projetam-se sugestões dos universitários para melhoria e maior desenvolvimento do curso. As respostas apresentadas representam 19\% (11alunos) e as sugestões, vão desde melhorar a postura docente, ter mais paciência no trato com os estudantes, falta de integração entre as áreas de Matemática e Física, até o fato do curso oferecer poucas 
disciplinas voltadas para licenciatura. Citam, inclusive, o fato de ser mais parecido com um bacharelado do que com um curso que forma, profissionais para atuar na docência. Nesse ínterim, nota-se o protagonismo dos acadêmicos como um fator preponderante para o desenvolvimento do curso, onde as opiniões devem ser valorizadas, principalmente em se tratando de uma avaliação. Zabalza (2007), nos apresenta que:

\begin{abstract}
Por outro lado, tem sido constante vincular a formação universitária ao desenvolvimento da capacidade crítica dos estudantes: uma atitude contestatória, rebelde, inquisitiva, a qual não aceite respostas fáceis, a qual valorize a autonomia, a capacidade de tomar decisões e de assumir compromissos. Essa independência intelectual que constitui a marca da maturidade sempre foi um valor que fez parte da formação universitária. (ZABALZA, 2007, p. 44)
\end{abstract}

Frente ao exposto, nota-se que o curso na visão dos discentes não está oferecendo uma formação inicial sólida, pois a busca pela melhoria do desenvolvimento do curso também parte de um dos quatro pilares da educação para o século XXI o de aprender a viver, de acordo com Delors (2004, p. 96), pois, “sem dúvida está aprendizagem representa, hoje em dia, um dos maiores desafios do ensino".

A categoria 4 é representada por 7\% (05 discentes) que não responderam à questão, enquanto no grupo 5, temos aprendizes que relatam o contrário do mencionado na categoria 3 , ou seja, que o curso proporciona sim, formação sólida e oportunidade de emprego.

Em conformidade com as respostas, cita-se o próprio PPC (2015) tendo como base o perfil profissional que a licenciatura pretende formar "Os egressos devem apresentar domínio de saberes matemáticos e físicos, bem como as formas, maneiras e diversidade em apresentar, transmitir e orientar estes mesmos conhecimentos para alunos da educação básica" (UFOPA, 2015, p.27). Nota-se que, somente 5,4\% (04 acadêmicos) têm a premissa que o curso está de fato proporcionando uma formação sólida contemplando todas as competências e habilidades propostas pela grade curricular. O que de fato representa um número pequeno, perto do montante das respostas e categorias anteriores. Ressalta-se que, de modo geral o curso apresenta na visão dos alunos, pontos importantes e que através da reformulação do curso pode-se melhorar a formação destes futuros profissionais.

A categoria 6 apresenta informações tais como sobrecarrega do discente; disciplinas extensas e carga horária excessiva. Conforme já mencionado, a aprovação do PPC foi anterior a homologação da Resolução nº 2, de $1^{\circ}$ de julho de 2015 que define as Diretrizes Curriculares Nacionais para a formação inicial em nível superior (cursos de licenciatura, cursos de formação pedagógica para graduados e cursos de segunda licenciatura), com as novas discussões e as 
recomendações do MEC, os cursos reformularão suas grades curriculares a fim de atender as novas exigências.

Após serem instigados a refletir sobre sua opinião em relação ao curso, foi solicitado que os discentes listassem os pontos que consideraram negativos no curso? A seguir apresentase o Gráfico 2.

Gráfico 2 - Pontos negativos elencados pelos discentes do curso de LIMF

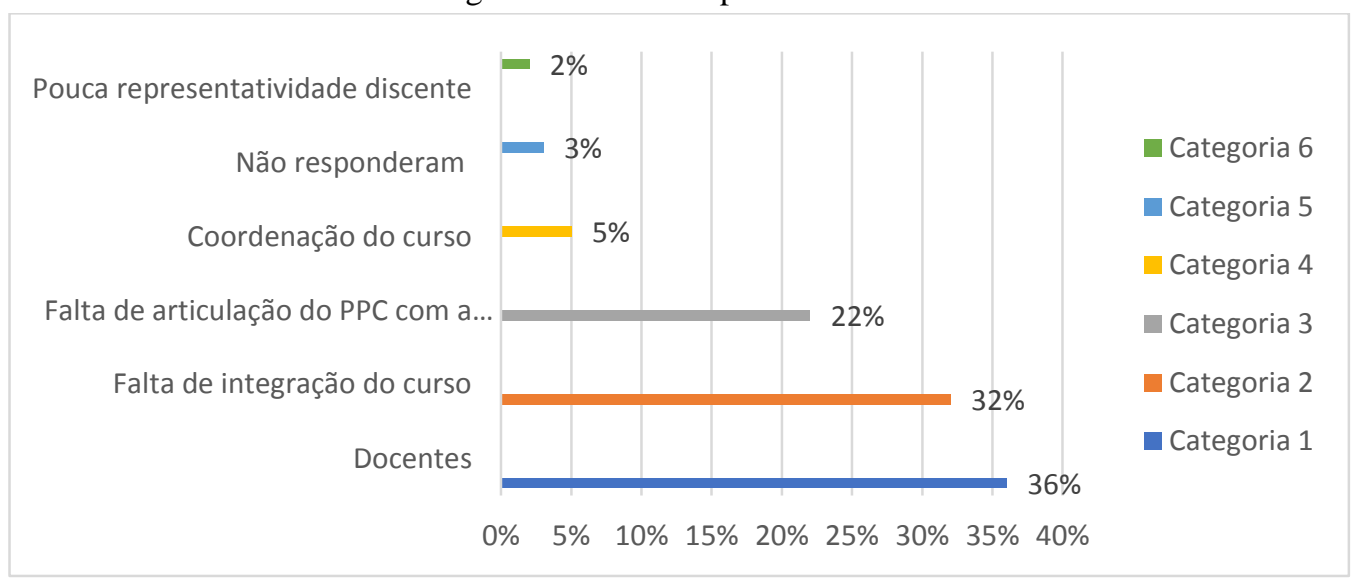

Fonte: Questionário aplicado na avaliação interna do curso 2017.

A categoria 1, versou sobre os docentes. Os acadêmicos elencaram algumas situações que na visão dos mesmos poderia melhorar, cita-se algumas que compõem esta categoria: despreparo dos professores, falta de didática e compromisso, nos remete a um dos pontos tratados aqui, pois Imbernón (2011), nos coloca que“ a função de "propor valores" é uma tarefa educativa complexa e às vezes contraditória, já que não se obterá a formação dos indivíduos unicamente com a interação social, que apresenta aspectos muito problemáticos em uma sociedade pluralista. (IMBERNÓN, 2011, p.33).

No item, professor não comprometido com a qualidade de ensino, se faz necessário nos remeter ao documento "Educação: um tesouro a descobrir, relatório para a UNESCO da Comissão Internacional sobre Educação para o Século XXI", onde se retrata, orientações que vão desde a educação básica à universidade, que preconiza sobre o ato de ensinar e as dificuldades do ofício de ser professor.

Mesmo que o ofício de professor seja, fundamentalmente, uma atividade solitária, no sentido de que cada professor deve assumir suas próprias responsabilidades e deveres profissionais, o trabalho em equipe é indispensável, sobretudo no secundário, para melhorar a qualidade da educação e adaptá-la melhor às características particulares das aulas ou dos grupos de alunos (DELORS, 2004, p. 33).

Rabelo (2019), em uma pesquisa recente realizada com a turma de 2017 de LIMF, retrata através da percepção dos discentes ser uma realidade o uso intensivo de métodos tradicionais. 
Como proposta, a autora coloca que os docentes busquem o embasamento necessário de suas atividades com a inserção do uso das tecnologias como mediadoras do processo de aprendizagem dos discentes em sua rotina diária. Por conseguinte, desta maneira também proporcionando uma maior interação entre docentes e discentes, fato este também relatado no item 10: falta de comunicação entre professor/aluno.

Na categoria 2, 22\% (correspondentes a 23 alunos) relatam a ausência de integração e desorganização de horários como sendo um dos pontos mais negativos encontrados pela maioria dos discentes, seguindo do questionamento que o curso não é integrado à física, professores que não concordam com o curso ser integrado e acabam por não contribuir para o desenvolvimento e melhoria. Em suma, os discentes declaram que a licenciatura assume um caráter de bacharelado. É notório um impasse quanto a separação da formação integrada, em dois (um de física e o outro de matemática), por várias alegações: falta de integração das áreas; falta de integração dos docentes; carga horaria excessiva; em outras informações obtidas cita-se a carga horária baixa, para alguns componentes curriculares, pois acreditam que não terão uma boa formação na área de física, falta de planejamento e o uso de métodos tradicionais, dentre outras coisas.

Frente ao exposto, citaremos o que dispõem na categoria 3 que contém como ponto negativo, o conteúdo de matemática, ou seja, os professores que ignoram o que está previsto no PPC. Estas informações denunciam que os docentes não estão seguindo o que dispõem as ementas dos conteúdos curriculares propostos no PPC, mesmo sabendo que o PPC é um documento que norteiam as ações do curso e que não deve ser desconsiderado, tendo em vista sua importância para construir o perfil dos profissionais. Ainda discutindo sobre a premissa pela qualidade da educação temos também, disciplinas com incompatibilidade ao objetivo do curso, fato este que não deveria estar acontecendo, sendo citado por 6\% (05) dos discentes corroboramos com as ideias de Imbernón (2011, p.42) “o tipo de formação inicial que os professores costumam receber não oferece preparo suficiente para aplicar uma nova metodologia, nem para aplicar métodos desenvolvidos teoricamente em sala de aula".

$\mathrm{Na}$ categoria 4, coordenação do curso, apresentam-se como inferências uma melhor organização administrativa, pois os universitários consideram que as férias dos docentes ao longo do período letivo atrapalham o desenvolvimento e a regularização do calendário.

A categoria 5 foi composta por aprendizes que não responderam à pergunta totalizando $3 \%$ (02 discentes). 
Na categoria 6 temos pouca representatividade, inclusive na construção ou reformulação do PPC.

Na questão 3, foi solicitado aos mesmos uma classificação de eventuais aquisições obtidas, em relação ao curso, através da marcação de opção que mais se aproximavam das obtidas ao longo do curso, durante o desenvolvimento das ações de graduação. A seguir, apresentamos os resultados, indicados no Gráfico 3.

Gráfico 3 - Eventuais aquisições obtidas no curso

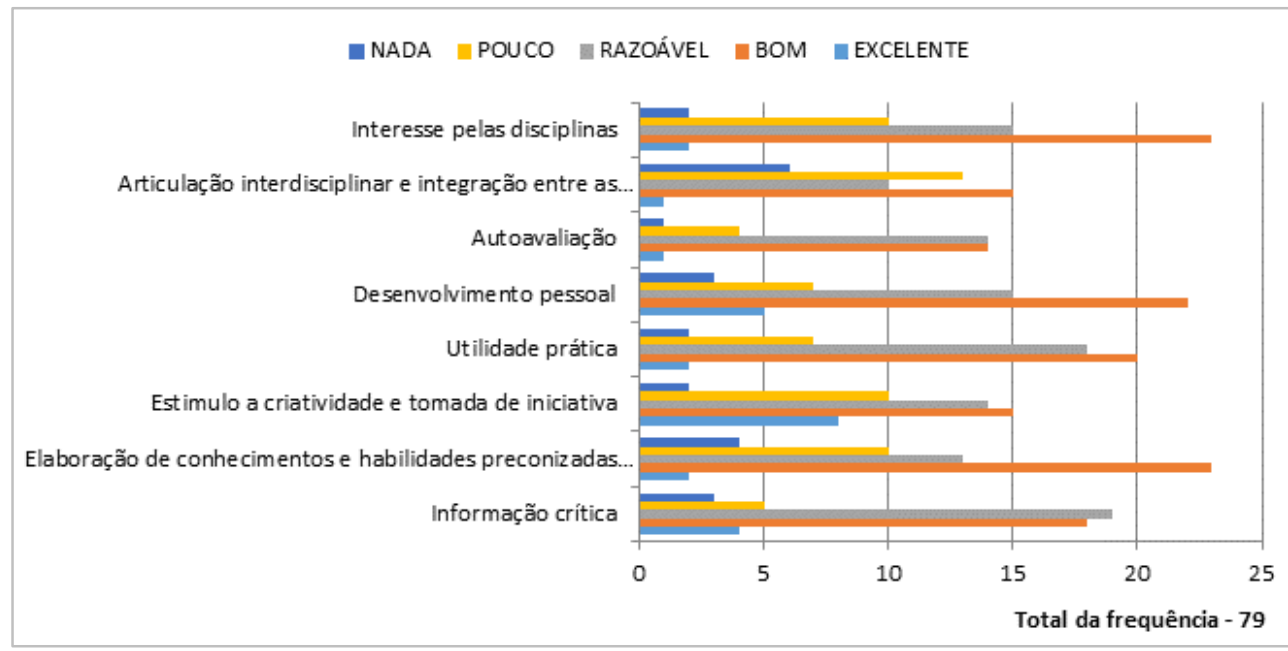

Fonte: Questionário aplicado na avaliação interna do curso, 2017.

Com relação a esta questão, os aspectos positivos estão relacionados ao aprofundamento dos conhecimentos, ao fato do curso ter uma utilidade prática. Em uma questão específica, sobre quais pontos auxiliou o discente, os itens: desenvolvimento pessoal, elaboração de conhecimentos e habilidades e interesse pelas disciplinas apresentaram melhores índices dentro da formação oferecida, cerca da metade das respostas sendo razoável, bom e/ou excelente. Os aspectos a serem melhorados são bastante variados. Referem-se à falta de estímulo e tempo para que os alunos discutam/apresentem seus pensamentos, seus argumentos. Há também uma relação com a formação em física, pois surgiram comentários sobre haver poucas disciplinas de física, ser mais teórica, e não se relacionar diretamente com a matemática.

Com relação à Questão 4, foi solicitado que os mesmos apresentassem um olhar crítico sobre os professores, das disciplinas, com base em algumas informações pertinentes, ao cotidiano de sala de aula, questões relativas a expertise do docente, além das relações estabelecidas ao longo da convivência do dia-a-dia.

No Gráfico 4, apresentamos as informações fornecidas pelos discentes. 
Gráfico 4 - Informações sobre os docentes

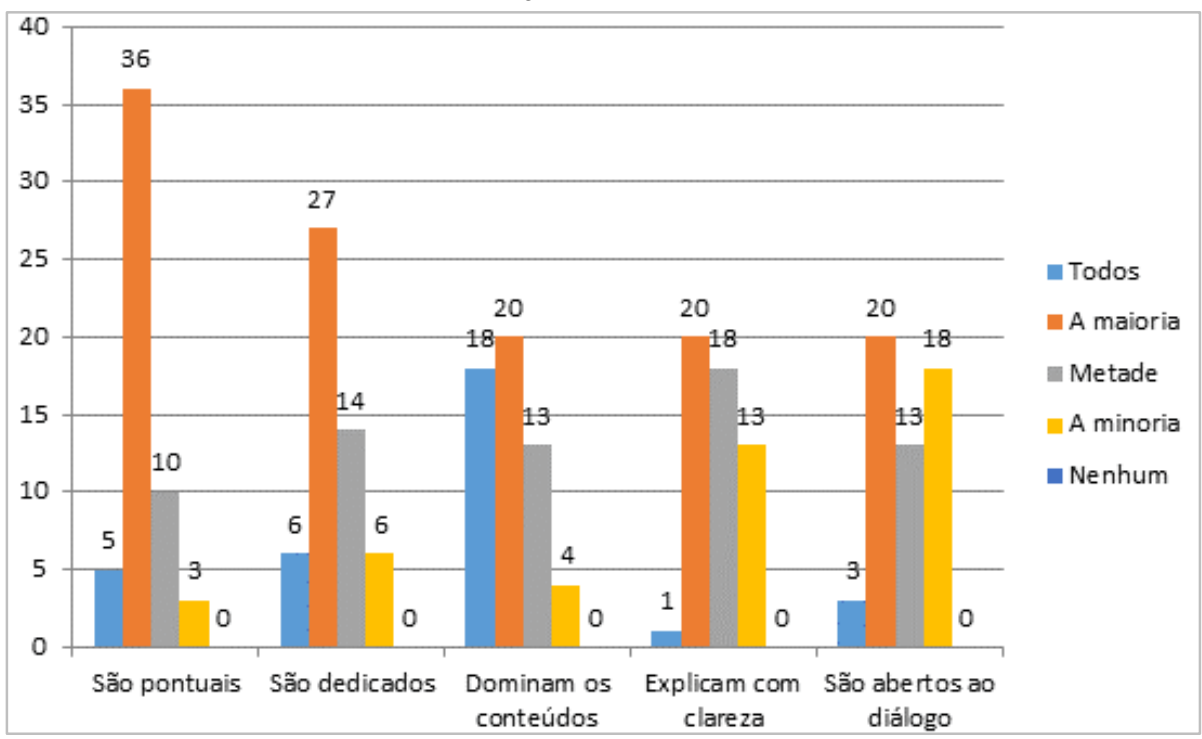

Fonte: Questionário aplicado na avaliação interna do curso, 2017.

Em adição, solicitamos que pontuassem alguns comentários e observações específicas, sobre os docentes. As informações fornecidas indicaram as seguintes características: i) falta de comunicação/diálogo entre docentes; ii) professores com características de licenciatura; iii) professores comprometidos; iv) atrasos e faltas de professores específicos; v) professores reverem didática; vi) abertura ao diálogo; vii) ouvir e ignorar; viii) professor de cálculo saber transmitir o assunto; ix) professor não domina o assunto.

Na questão 5, foi solicitado uma nota, na escala de 0 a 10, como uma forma de avaliar o curso, em termos do corpo docente, na totalidade, a infraestrutura proporcionada pelo curso, no desenvolvimento das ações de graduação e a coordenação do curso, conforme informado no Gráfico 5.

Gráfico 5 - Avaliação do curso pelos discentes: visão macro

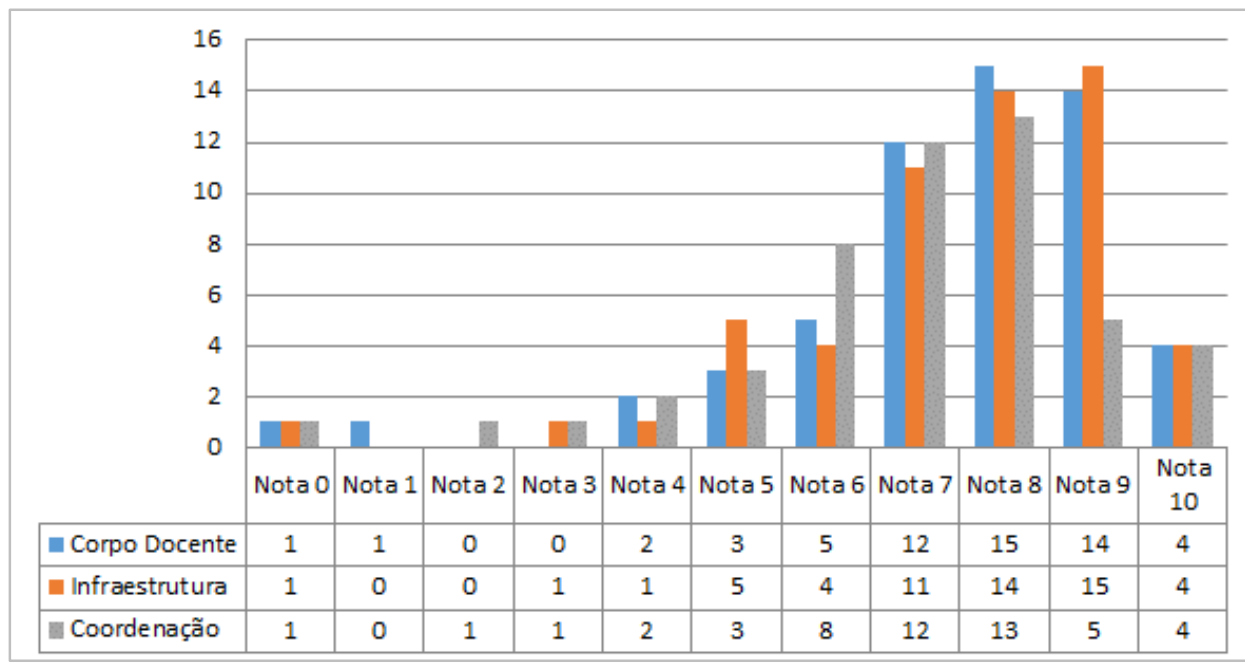

Fonte: Questionário aplicado na avaliação interna do curso, 2017. 
Em relação a questão 6, foi inquirido se o educando possui conhecimento ou se já leu o PPC do curso. A partir das informações apresentadas no Gráfico 6 abaixo, verificamos que boa parte educandos que responderam o questionário (75\%), tem conhecimento ou já leu o PPC LIMF.

Gráfico 6 - Conhecimento do PPC do curso de LIMF

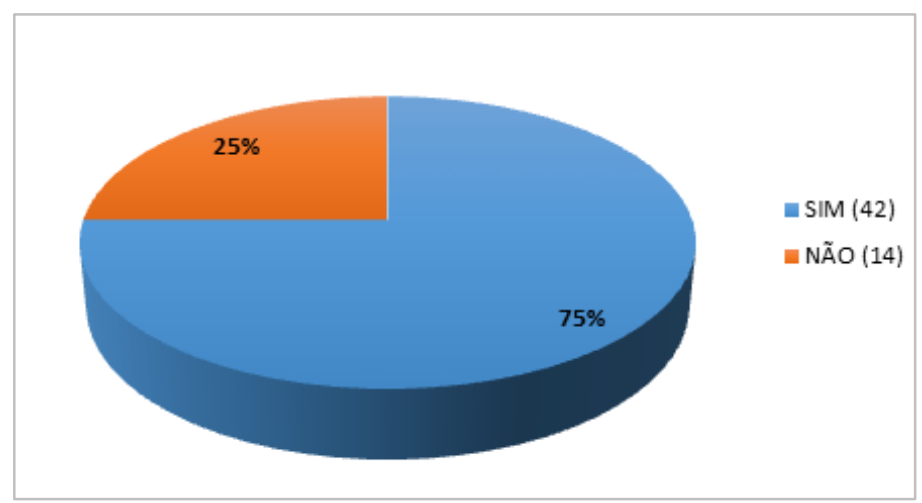

Fonte: Questionário aplicado na avaliação interna do curso, 2017.

Nas questões 7 e 8, foram perguntados, respectivamente 7) Que outro curso além do de LIFM e LIE, você entende que deveria ser ofertado, no PCE e 8) Você concorda que a graduação em LIMF deveria continuar ou ser extinto? Explicite seus argumentos! Algumas respostas estão indicadas no Gráfico 7, abaixo:

Gráfico 7 - Respostas relacionadas como as questões 7 e 8

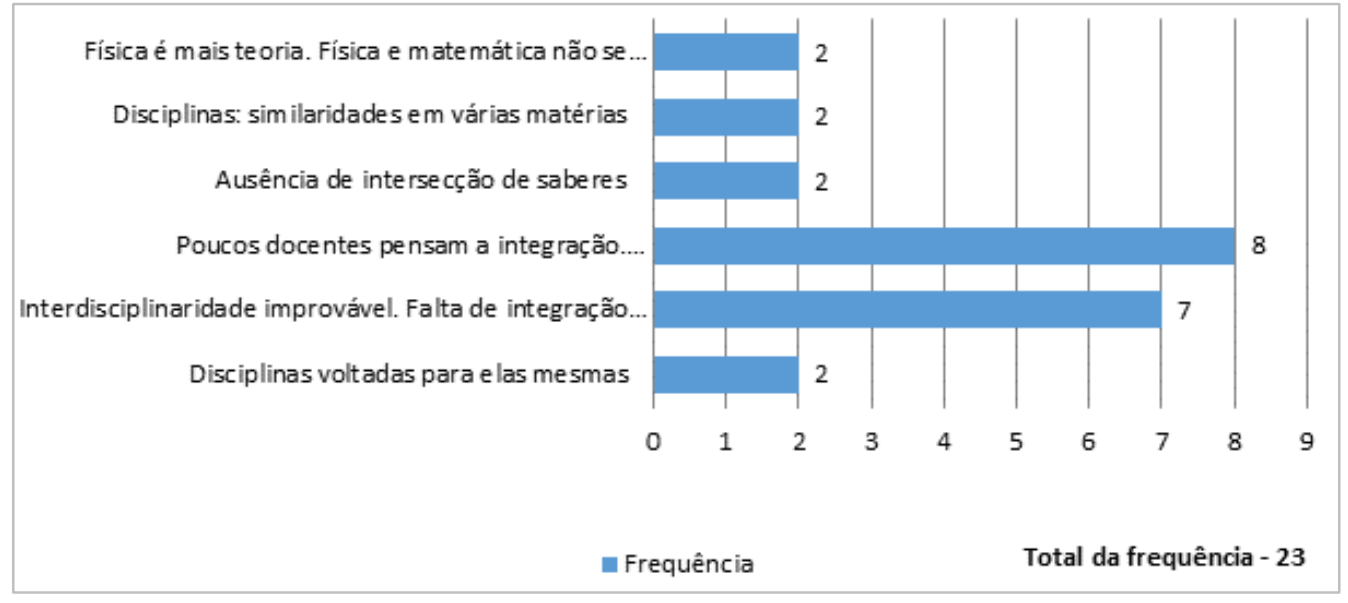

Fonte: Questionário aplicado na avaliação interna do curso, 2017.

Por fim, foi solicitado, na questão 9, o estabelecimento de sugestões e comentários para a melhoria do curso, além de outras sugestões que achar conveniente.

\section{Gráfico 8 -}




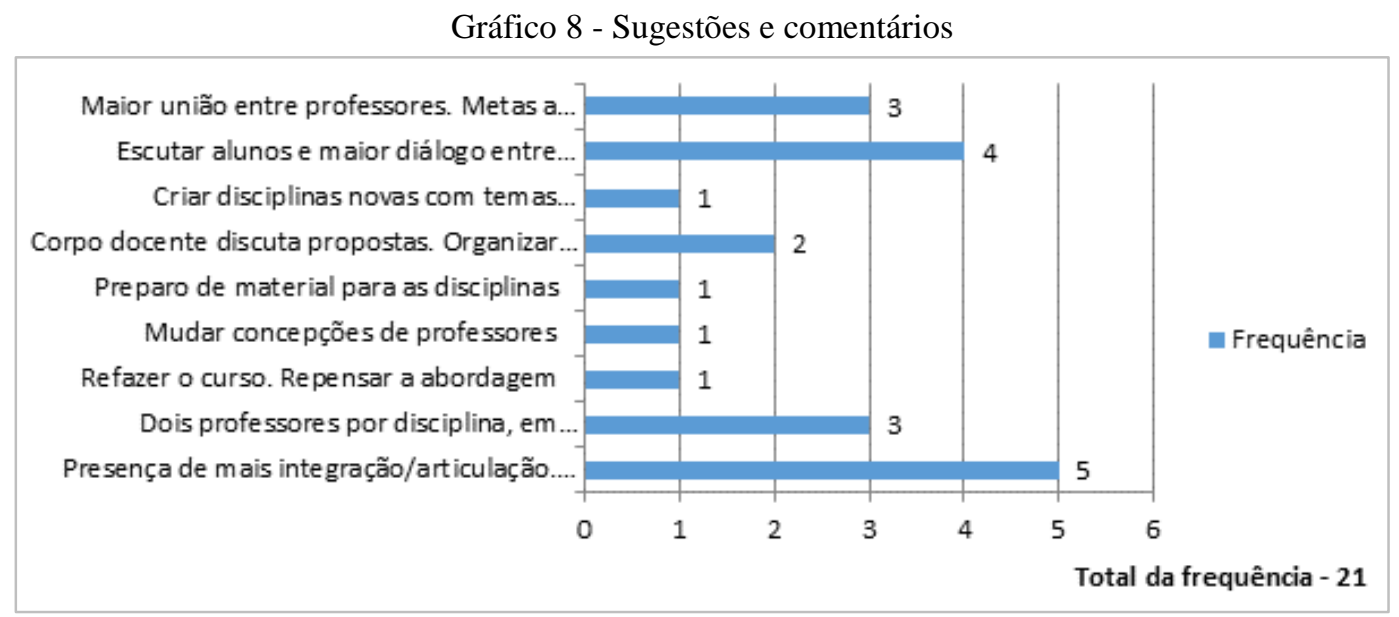

Fonte: Questionário aplicado na avaliação interna do curso, 2017.

De posse das respostas obtidas, realizamos leituras flutuantes, de modo a percebermos possíveis intersecções e distanciamentos nas falas apresentadas. Escolhemos realizar uma análise categorial, segundo Bardin (2011), por considerarmos mais adequada aos nossos objetivos. Que era refletir sobre o curso, ressaltamos que nossa análise se baseou no conjunto das respostas, de modo que pudéssemos levantar percepções na totalidade, as quais apresentamos a seguir.

\section{COMENTANDO AS INFORMAÇõES APRESENTADAS PELOS DISCENTES DE LIMF}

Optamos por esse olhar mais abrangente, pois nos permite uma percepção mais aprofundada dos diferentes olhares de nossos discentes. Um dos tópicos apontados, como positivo, foi o da Infraestrutura. Como a UFOPA é uma Universidade nova, ainda em estruturação física, temos, no ICED, um espaço físico apropriado, foi percebido por alguns. Já entre os pontos a serem melhorados, foi citada a quantidade de livros, didáticos ou não, e auxílios para maior aprofundamento teórico e prático de equipe ou de materiais. Esse ponto nos indica uma postura ativa dos acadêmicos, no sentido do melhoramento de seus conhecimentos. Há ainda dois pontos a serem aperfeiçoados, que foram apontados, que dependem mais da própria instituição do que dos formadores: a regularização do calendário acadêmico e maior participação do coordenador.

Em relação aos docentes, as informações apresentadas, de uma forma geral, projetam o surgimento de aspectos a serem melhorados, tais como serem mais abertos ao diálogo e a necessidade de se melhorar a integração e contextualização nas aulas, tornando o curso menos fragmentado. Como sugestões de melhoria para esses pontos, sugerem que existam ciclos de 
integração com professores - "interação interpessoal” - de modo a estreitar relações humanas no curso.

Em relação aos aspectos formativos e a proposta de integração, vinculada a natureza do curso, surge a percepção de alguns em tomar consciência da importância da proposta, ancorada em uma perspectiva de desenvolvimento profissional inovadora, para a região. Em que pese as dificuldades e obstáculos identificados por muitos dos respondentes, tais como: i) uma melhor organização e distribuição dos conteúdos nas disciplinas; ii) semelhança de um curso de bacharelado, iii) maior articulação dos conteúdos à educação básica, surgiram propostas dos discentes em: i) maior integração entre as disciplinas; ii) maior oferta de ações extensionistas; iii) criação de disciplinas novas com temas integrados; iv) articular a grade curricular por área, aproximando mais as disciplinas ao fato de ser uma licenciatura.

Por meio das informações obtidas e inferências das análises realizadas, na seção anterior, conclui-se que, ainda carece de muitas discussões e de uma compreensão maior do significado e concepção de um curso integrado ou interdisciplinar, pois não há ainda uma clareza satisfatória, na operacionalização de ações docentes, relacionadas a articulação do professor, em sala de aula. Entendemos que tal dificuldade, pode estar relacionada com a nossa cultura disciplinar de formação e a falta de ações de planejamento efetivas para executar ou vivenciar experiências docentes articuladas aos conhecimentos físicos e matemáticos.

Em que pese os esforços das gestões que atuaram na coordenação do curso, para a melhoria do mesmo, percebe-se que ainda falta muito a melhorar. Este instrumento de avaliação, na forma de um questionário aplicado, e as informações obtidas, através do mesmo, puderam fornecer subsídios para a atuação, por parte do Núcleo Docente Estruturante do curso de LIMF, no sentido de discutir melhorias, e que atualmente estão sendo objeto de análise e discussão. Tais encaminhamentos, certamente, trarão bons elementos a serem considerados, no processo de avaliação do curso e a previsão de uso dos instrumentos de avaliação interna, preconizados no seu PPC.

Através dos dados apresentados, percebe-se a necessidade de um contínuo aperfeiçoamento do PPC, além da carência de revisões periódicas e necessárias, visando a implementação de uma cultura de avaliação e monitoramento da qualidade do curso. Entendemos que tais encaminhamentos, podem fornecer um caminho, para um processo de formação, contemplando assim, os objetivos, competências e habilidades que embasam a instrução destes, projetadas no PPC do curso e a necessidade de efetivação contínua de um processo de apreciação do curso de LIMF. 


\section{REFERÊNCIAS}

ASSIS, Alessandra Santos de. Didática, o ensino na licenciatura e as tecnologias da informação e da comunicação. In: D’AVILA, Cristina; VEIGA, Ilma Passos (Org.) Didática e docência na educação superior: implicações para a formação de professores. Campinas SP: Papirus, 2012.

BARDIN, Laurence. Análise de Conteúdo. Edições 70. Lisboa, 2011.

BRASIL, CONSELHO NACIONAL DE EDUCAÇÃO DO MINISTÉRIO DA EDUCAÇÃO.

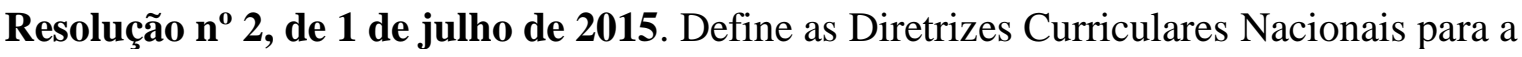
formação inicial em nível superior (cursos de licenciatura, cursos de formação pedagógica para graduados e cursos de segunda licenciatura) e para a formação continuada. Disponível em: http://portal.mec.gov.br/secretaria-de-regulacao-e-supervisaoda-educacao-superiorseres/323-secretarias-112877938/orgaos-vinculados-82187207/21028-resolucoes-doconselho-pleno-2015. Acesso em: 28 de maio de 2017.

BRASIL. Lei no 13.005, de 25 de junho de 2014. Aprova o Plano Nacional de Educação PNE e dá outras providências. Diário Oficial da União, Brasília, 26 de junho de 2014. Disponível em: 〈http://www.planalto.gov.br/ccivil_03/_ato2011-2014/2014/lei/113005.htm>. Acesso em: 23 mar. 2017.

BRASIL, MINISTÉRIO DA EDUCAÇÃO. Lei 9.394/96, de Diretrizes e Bases da Educação Brasileira - LDB. 2017. Disponível em http://www2.senado.leg.br/bdsf/bitstream/handle/id/529732/lei_de_diretrizes_e_bases_1ed.pd f. Acesso em 01 de fev. de 2019.

BRASIL. INSTITUTO DE PESQUISA ECONÔMICA APLICADA. Professores da educação básica no Brasil: condições de vida, inserção no mercado de trabalho e remuneração. Instituto de Pesquisa Econômica Aplicada - Brasília: Rio de Janeiro: IPEA. 2017. Disponível em: http://repositorio.ipea.gov.br/bitstream/11058/7929/1/td_2304.pdf Acesso em: 23 mar. de 2019.

DELORS, Jacques. Educação: um tesouro a descobrir. 8. Ed. São Paulo: Cortez; Brasília, DF: MEC: UNESCO, 2004.

D’AMBRÓSIO, Ubirantan. Educação Matemática: da teoria à prática. 12 ed. Campinas SP: Papirus, 1996. (Coleção Perspectivas em Educação Matemática)

IMBERNÓN, Francisco. Formação docente e profissional: formar a mudança e a incerteza. 9.ed. São Paulo: Cortez, 2011. (Coleção questões da nossa época; v. 14)

LIBÂNEO, José Carlos. Didática. São Paulo: Cortez, 1992.

MARCONI, Marina de Andrade; LAKATOS, Eva Maria. Técnicas de pesquisa: planejamento e execução de pesquisas, amostragens e técnicas de pesquisa, elaboração, análise e interpretação de dados. $7^{\circ}$ ed. São Paulo: Atlas, 2011.

RABELO, Neliane Mota. TIC NA FORMAÇÃO INICIAL: uma visão de futuros professores de dois cursos de licenciatura da UFOPA. Dissertação (Mestrado) - 
Universidade Federal do Oeste do Pará, Instituto de Ciências da Educação, Programa de PósGraduação em Educação, Santarém, 2019.

UNIVERSIDADE FEDERAL DO OESTE DO PARÁ. RESOLUÇÃO 125/2015, de 22 de setembro de 2015. Aprova o Projeto Político Pedagógico do curso de Licenciatura Integrada em Matemática e Física, da Universidade Federal do Oeste do Pará.

VERGANI Teresa. Excrementos do sol: a propósito de diversidades culturais. Portugal: Pandora, 1995.

Recebido em: 28 de maio de 2019. Aprovado em: 22 de outubro de 2019. 